\title{
Intraocular pressure in retinal vein occlusion
}

\author{
JOSEPH FRUCHT, AMIRAM SHAPIRO, AND SAUL MERIN \\ From the Department of Ophthalmology, Hadassah University Hospital, Ein Karem, Jerusalem, Israel
}

SUMMARY The intraocular pressure of 59 patients with retinal vein occlusion was studied. Central retinal vein occlusion (CVO) was diagnosed in 24 patients and branch retinal vein occlusion (BVO) was diagnosed in the rest. The intraocular pressure of a sex and age matched group of controls was also studied for comparison. The intraocular pressure in the CVO group were significantly different from those of the matched controls $(p<0.001)$. A statistically significant difference of a lesser degree $(p<0.05)$ was also found in a comparison of the intraocular pressures of the BVO group with those of their sex and age matched group of controls. These findings may indicate the possible role of increased intraocular pressure in the pathogenesis of CVO and BVO.

Retinal vein occlusion (RVO) is a rather common vasculopathy, mainly affecting the adult and the elderly populations. Clinically it may appear in form of a central retinal vein occlusion (CVO) or in the form of a branch retinal vein occlusion (BVO), 2 different manifestations of one disease or possibly 2 different diseases. Many systemic diseases may be associated with RVO. ${ }^{1-3}$ Ocular and periocular diseases may also cause vein occlusion ${ }^{4}$; open-angle glaucoma is one of them. Between $10 \%$ and $50 \%$ of patients with CVO have been found to have an openangle glaucoma, ${ }^{56}$ but patients with BVO have no increased incidence of open-angle glaucoma.'

In the present study we examined the intraocular pressure in patients with RVO in order to find out if an increased intraocular pressure without manifest glaucoma may be associated with an increased incidence of retinal vein occlusion.

\section{Materials and methods}

Fifty-nine patients with retinal vein occlusion were examined as part of an epidemiological study of retinal venous occlusion in Israel. Central retinal vein occlusion was diagnosed in 24 patients (13 males and 11 females) with a mean age of $57 \cdot 9$ years, $S D \pm 12 \cdot 1$. Branch vein occlusion was diagnosed in 35 patients (15 males and 20 females) with a mean age of $59 \cdot 5$ years, $S D \pm 9 \cdot 8$. The first intraocular pressure measurement at or after the event of vein occlusion was recorded in all the cases and evaluated.

A control group was randomly chosen from our general outpatient clinic. This group included Correspondence to Dr J. Frucht. patients who were examined by residents in ophthalmology during 6 successive working days of the clinic. Patients who had intraocular inflammations, recent trauma, glaucoma, or had gone less than one year after surgery or were treated by pressure affecting drugs were excluded from the study. The intraocular pressures in both eyes were measured in each case.

A matching* of age and sex between the controls and those with vein occlusion was carried out. The mean age of the matched controls was 57.54 years $(\mathrm{SD} \pm 13 \cdot 3)$ for the CVO group and $59 \cdot 3$ years $(\mathrm{SD} \pm 10 \cdot 3)$ for the BVO group. In addition the intraocular pressure of the similar eyes was compared between the matched and the affected patients.

\section{Results}

In the group of patients with the central vein occlusion the intraocular pressures were between $12-23 \mathrm{mmHg}$ with a mean intraocular pressure of $16 \cdot 87, \mathrm{SD} \pm 2 \cdot 82$ (Table 1). The intraocular pressures in the fellow eyes (not affected) did not differ from the pressures in the affected eyes. However, a very significant difference

${ }^{*}$ The patients with the vein occlusion were numbered by the Institute for Prevention of Blindness and the matching was done according to these numbers. Number 1 was first to be matched and so on. The controls were numbered successively according to the date of the examination and the place of the patient's file among all the other files of the clinic of the same day. Matching of the affected patient by the same age and sex of the first suitable numbered control was done in each case. If no exact age matching was available, the closest control of the same sex was matched, the search being started from the beginning of the control list. The maximal age disparity between the groups was 5 years in several cases. However, most of the patients were matched within the limits of 2 years of age. 
Table 1 Intraocular pressures in the affected patients and the controls

\begin{tabular}{|c|c|c|c|c|c|c|c|c|c|}
\hline \multirow[b]{3}{*}{ No. } & \multicolumn{4}{|c|}{ Intraocular pressure in $\mathrm{mm} \mathrm{Hg}$} & \multicolumn{5}{|c|}{ Intraocular pressure in $\mathrm{mm} \mathrm{Hg}$} \\
\hline & \multicolumn{2}{|c|}{ Central vein occlusion } & \multicolumn{2}{|l|}{ Controls } & \multicolumn{3}{|c|}{ Branch vein occlusion } & \multicolumn{2}{|l|}{ Controls } \\
\hline & $\begin{array}{l}\text { Affected } \\
\text { eye }\end{array}$ & Fellow eye & $\begin{array}{l}\text { Matched } \\
\text { eye }\end{array}$ & Fellow eye & No. & $\begin{array}{l}\text { Affected } \\
\text { eye }\end{array}$ & Fellow eye & $\begin{array}{l}\text { Matched } \\
\text { eye }\end{array}$ & $\begin{array}{l}\text { Fellow } \\
\text { eye }\end{array}$ \\
\hline 1 & 20 & 19 & 16 & 16 & 1 & 14 & 13 & 14 & 12 \\
\hline 2 & 18 & 18 & 14 & 12 & 2 & 14 & 15 & 14 & 16 \\
\hline 3 & 18 & 16 & 14 & 14 & 3 & 14 & 13 & 12 & 13 \\
\hline 4 & 12 & 11 & 16 & 16 & 4 & 15 & 16 & 14 & 14 \\
\hline 5 & 17 & 18 & 10 & 10 & 5 & 12 & 14 & 16 & 16 \\
\hline 6 & 14 & 13 & 12 & 12 & 6 & 14 & 16 & 12 & 12 \\
\hline $7^{*}$ & 23 & 60 & 16 & 16 & 7 & 12 & 16 & 14 & 14 \\
\hline 8 & 18 & 12 & 8 & 8 & $8^{*}$ & 18 & 67 & 8 & 8 \\
\hline 9 & 15 & 14 & 14 & 14 & 9 & 20 & 20 & 14 & 12 \\
\hline 10 & 17 & 18 & 14 & 14 & 10 & 16 & 20 & 16 & 14 \\
\hline 11 & 15 & 14 & 16 & 16 & 11 & 20 & 19 & 12 & 16 \\
\hline 12 & 12 & 20 & 14 & 16 & 12 & 17 & 16 & 16 & 16 \\
\hline 13 & 16 & 16 & 12 & 12 & 13 & 18 & 17 & 12 & 12 \\
\hline 14 & 18 & 16 & 12 & 12 & 14 & 22 & 21 & 12 & 12 \\
\hline 15 & 14 & 15 & 12 & 15 & 18 & 12 & 12 & 12 & 12 \\
\hline 16 & 15 & 12 & 10 & 10 & 16 & 16 & 20 & 15 & 16 \\
\hline 17 & 19 & 19 & 12 & 12 & 17 & 15 & 15 & 12 & 14 \\
\hline 18 & 18 & 12 & 14 & 14 & 18 & 16 & 17 & 14 & 12 \\
\hline 19 & 12 & 12 & 16 & 16 & 19 & 11 & 12 & 14 & 13 \\
\hline 20 & 19 & 18 & 14 & 14 & 20 & 12 & 12 & 12 & 12 \\
\hline 21 & 17 & 15 & 12 & 12 & 21 & 18 & 20 & 16 & 16 \\
\hline 22 & 20 & 18 & 16 & 12 & 22 & 12 & 12 & 14 & 14 \\
\hline 23 & 20 & 19 & 14 & 13 & 23 & 18 & 14 & 15 & 14 \\
\hline \multirow[t]{3}{*}{24} & 18 & 17 & 18 & 17 & 24 & 17 & 16 & 14 & 14 \\
\hline & & & & & 25 & 10 & 10 & 16 & 15 \\
\hline & & & & & 26 & 12 & 12 & 16 & 16 \\
\hline \multirow[t]{2}{*}{$\overline{\mathbf{x}}$} & $16 \cdot 87$ & $15 \cdot 82$ & $13 \cdot 24$ & $13 \cdot 33$ & 27 & 19 & 18 & 14 & 14 \\
\hline & & & & & 28 & 15 & 15 & 12 & 12 \\
\hline \multirow[t]{9}{*}{ S.D. } & $\pm 2 \cdot 87$ & $\pm 2 \cdot 82$ & $\pm 2 \cdot 4$ & $\pm 2 \cdot 32$ & 29 & 15 & 12 & 14 & 14 \\
\hline & & & & & 30 & 12 & 12 & 18 & 15 \\
\hline & & & & & 31 & 16 & 15 & 16 & 16 \\
\hline & & & & & 32 & 15 & 19 & 17 & 18 \\
\hline & & & & & 33 & 20 & 12 & 12 & 12 \\
\hline & & & & & 34 & 9 & 11 & 16 & 16 \\
\hline & & & & & 35 & 14 & 14 & 10 & 10 \\
\hline & & & & & $x$ & $15 \cdot 2$ & $15 \cdot 17$ & $13 \cdot 88$ & $13 \cdot 77$ \\
\hline & & & & & SD & \pm 3.08 & \pm 3.07 & $\pm 2 \cdot 11$ & \pm 2.07 \\
\hline
\end{tabular}

* Secondary glaucoma found in the fellow eye of the affected eye; therefore this case was excluded from the statistical calculations comparing the affected eye with the fellow eye. In addition this fellow eye was not included in the mean and SD results.

between the intraocular pressures in the affected eyes and the controls was shown ( $t$ test, $t=7 \cdot 74, \mathrm{p}<0 \cdot 001)$. A statistical difference, but less significant, was found between the affected eyes in the central vein occlusion and the affected eyes in the branch vein occlusion groups $(t$ test, $t=2 \cdot 159, \mathrm{p}<0 \cdot 02)$.

The distribution of the intraocular pressures within the branch vein occlusion group were $9-22 \mathrm{mmHg}$ (Table 1) with a mean intraocular pressure of $15 \cdot 2$, $\mathrm{SD} \pm 3.08$. The pressures in the affected eye were slightly different from the matched controls $(t$ test, $t=2 \cdot 089, \mathrm{p}<0 \cdot 05)$. Within the branch vein occlusion group there was no difference between the intraocular pressures in the affected and the unaffected eyes. Moreover, no statistical difference was recorded between the intraocular pressures in the matched eyes and the fellow eyes of the control groups.

\section{Discussion}

Chronic simple glaucoma is found in $10-50 \%$ of patients with central vein occlusion. ${ }^{56}$ The cause of this association is not entirely clear. Cell proliferation in the lumen of the vein at the level of the lamina cribrosa $^{8}$ or the loss of the glial tissue within the cup, in addition to the displacement of the vessels in the anterior portion of the optic nerve, ${ }^{9}$ were suggested as a cause of central vein occlusion.

Another possible mechanism is related to changes in the haemodynamics at the level of the lamina 
cribrosa. The ocular blood flow is chiefly determined by the level of the systemic arterial and intraocular pressures, the blood viscosity, and the state of the blood vessels supplying the eyes. ${ }^{10}$ One factor possibly associated with the pathogenesis of central vein occlusion is an apparent slowing or stasis of the blood column in the retinal veins. This may result from an increase in venous pressures and from decreased arterial blood flow. ${ }^{5} \mathrm{~A}$ rise in intraocular pressure above the normal gives a corresponding rise in intraocular venous pressure, leading to reduction in pressure head for the blood flow through the ocular tissue. However, compensatory increase of pressure in the arteries outside the eye ${ }^{11}$ and decreased vascular resistance in the retina ${ }^{12}$ compensate some of the pressure head decrease. As regards the perfusion pressure in the eye, a rise in the intraocular pressure has the same effect as a fall in the blood pressure.

Our group of patients with central vein occlusion had significantly higher intraocular pressures in the affected eye than the controls and statistically unchanged intraocular levels in the fellow eye. Although most of these intraocular pressures are within the so-called 'high normal levels of the intraocular pressures,' it may appear that, for this group of old patients with possible poor vasculature, reduced blood flow, and poor compensatory vascular mechanisms, these intraocular pressures are high enough to reduce the pressure head in the eye and thereby reduce the blood flow through the ocular tissue to such a level that stagnation of the blood column in the retina will occur, followed by vein thrombosis.

Hayreh et al. ${ }^{1314}$ reported a drop in IOP following the venous occlusive event. However, these investigators did not select their controls as an age matched group. They assumed that the drop of IOP is a result of the vein thrombosis. The significant difference between the intraocular pressures in the central vein occlusion and the branch vein occlusion groups shows a different cause for these 2 types of vasculopathy.

These findings may indicate the importance of raised intraocular pressure in the pathogenesis of some cases with CVO. They may also indicate that in adults and elderly patients with high intraocular pressure, as in intraocular hypertension without glaucoma, hypotensive treatment should be considered. It is also debatable whether the fellow eye with an equal intraocular pressure should be treated preventively to reduce the intraocular pressure.

\section{References}

1 Klein BA, Olwin JH. A survey on the pathogenesis of retinal vein occlusion. Arch Ophthalmol 1956; 56: 207-47.

2 Paton A, Rubinstein K, Smith VH. Arterial insufficiency in retinal venous occlusion. Trans Ophthalmol Soc UK 1964; 84: $559-95$.

3 Ackerman AL. The ocular manifestations of Waldenström's macroglobulinemia and its treatment. Arch Ophthalmol 1962; 67: 701-7.

4 Klein BA. Prevention of retinal venous occlusion. Am J Ophthalmol 1950; 33: 175-84.

5 Duane T. Clinical ophthalmology. Revised 3rd ed. New York: Harper and Row, 1981: 3: 2-3.

6 Vannas S, Tarkkanen A. Retinal vein occlusion and glaucoma; tonographic study of the incidence of glaucoma and its prognostic significance. Br J Ophthalmol 1960; 44: 583-9.

7 Becker B, Post LT. Retinal vein obstruction: clinical and experimental observations. Am J Ophthalmol 1951; 34: 677-86.

8 Verhoeff FH. Cited in Jaeger EA. Venous obstructive disease of the retina. In: Duane T. Clincial ophthalmology. Revised 3rd ed. New York: Harper and Row, 1980: 3: chapter 15:2.

9 Dobree $\mathrm{JH}$. Venous obstruction and neovascularization at the disc in chronic glaucoma. Trans Ophthalmol Soc UK 1957; 77: 229-38.

10 Wise GN, Dollery CT, Henkind P. The retinal circulation, New York: Harper and Row, 1971: 290-321.

11 Moses RA. Adler's physiology of the eye. 7th ed. New York: Mosby, 1981: 192-4.

12 Alm A, Bill A. The oxygen supply to the retina. II. Effects of high intraocular pressure and of increased arterial carbon dioxide tension on uveal and retinal blood flow in the cats. A study with labelled microspheres including flow determination in brain and some other tissues. Acta Physiol Scand 1972; 84: 306-19.

13 Hayreh SS, March W, Phelps CD. Ocular hypotony following retinal vein occlusion. Arch Ophthalmol 1978; 96: 827-30.

14 Hayreh SS, March W, Phelps CD. Ocular hypotony after retinal vascular occlusion. Trans Ophthalmol Soc UK 1977; 97: 757-67. 